Original Article

\title{
Probiotics and oral health : myth or reality?
}

\author{
Mamatha S. Shetty ${ }^{1} \&$ Yashaswini S. Shetty ${ }^{2}$ \\ ${ }^{1}$ Reader, Department of Periodontics, ${ }^{2}$ Intern, A.B. Shetty Institute of Dental Sciences, \\ Nitte University, Mangalore , Karnataka, India. \\ Correspondence \\ Yashaswini S. Shetty \\ Intern, A.B. Shetty Institute of Dental Sciences, Nitte University, M angalore 575 018, Karnataka, India. \\ Mobile : +91 9731669838 E-mail : shettyyashaswini@yahoo.com
}

\begin{abstract}
Human being ingests a large number of living microorganisms, predominantly bacteria. Although these organisms are naturally present in food and water, they can also be deliberately added during the processing of foods ${ }^{(1)}$. For several decades now, bacteria called Probiotics have been added to some foods because of their beneficial effects on human health. Several clinical studies have already demonstrated the effectiveness of certain probiotics in the treatment of systemic and infectious disease such as diarrhea, crohns disease, cardiovascular diseases, oropharyngeal infections and cancers ${ }^{2)}$.

Potential application of probiotics for oral health has recently attracted attention of several teams of researchers. The concept of probiotics therapy has been considered for application in oral health. Dental caries, periodontal diseases and halitosis are among the oral disorders that have been targeted. Hence, this section gives a brief idea of probiotics and its application in oral health.
\end{abstract}

Keywords : Probiotics, oral health, oral diseases.

\section{Introduction}

The role of diet in health and wellbeing is universally accepted with evolution of the science of nutrition, research is now being directed towards improving the understanding of specific physiologic effects of the diet beyond its nutritional effect ${ }^{(3)}$.In this aspect, probiotics are the subject of intense and widespread research in food and nutritional science.

Probiotics are described as "living microorganisms, principally bacteria, that are safe for human consumption, and when ingested in sufficient quantities, have beneficial effects on human health, beyond basic nutrition" (accepted by United Nations food and agriculture organization \& WHO) ${ }^{(4)}$ The term probiotic, meaning "for life", is derived from the Greek language, first probiotics species to be introduced in

Access this article online Quick Response Code

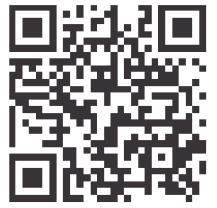
research was Lactobacillus acidophilus by Hull et al in 1984 followed by Bifidobacterium bifidum.

Characteristics of Probiotics As Cited By Who ${ }^{5)}$.
It should be a strain, which is capable of exerting a beneficial effect on the host, e.g. increased growth or resistance to a disease.

It should be non-pathogenic and non- toxic.

It should be stable and capable of remaining viable for periods under storage and field conditions.

It should not have an ability to transfer antibiotic resistance genes.

It should be able to maintain genetic stability in intestinal micro flora.

\section{How Probiotics Work?}

Several mechanism have been proposed to explain how probioticswork

these bacteria secrete various antimicrobials (Figure 1)

In addition they compete with various pathogenic agents for adhesion sites on the mucosa ${ }^{(6)}$.

Alteration of environmental condition of the oral cavity. probiotics provide beneficial effects by stimulating nonspecific immunity and modulating the humoral and cellular immune response ${ }^{(\eta)}$. 


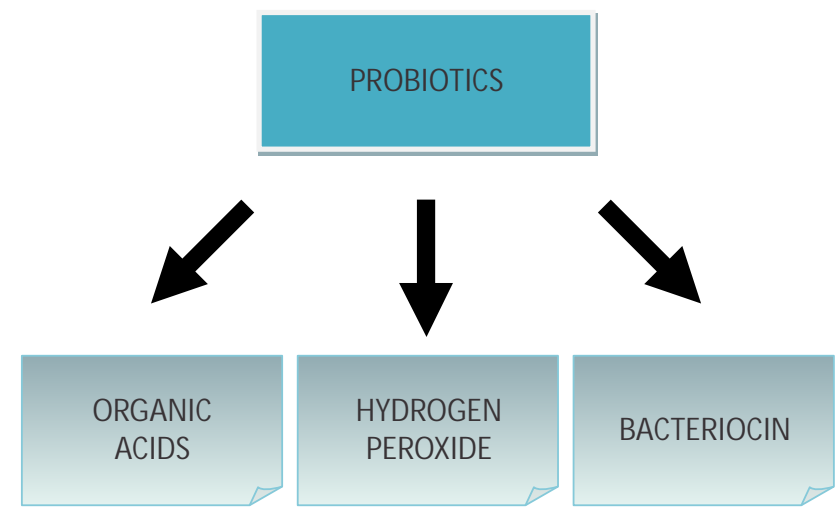

Fig. 1 Antimicrobials secreted byprobiotics

Probiotics Products Are Administered In Four Ways ${ }^{(8)}$ As Shown In: Table 1

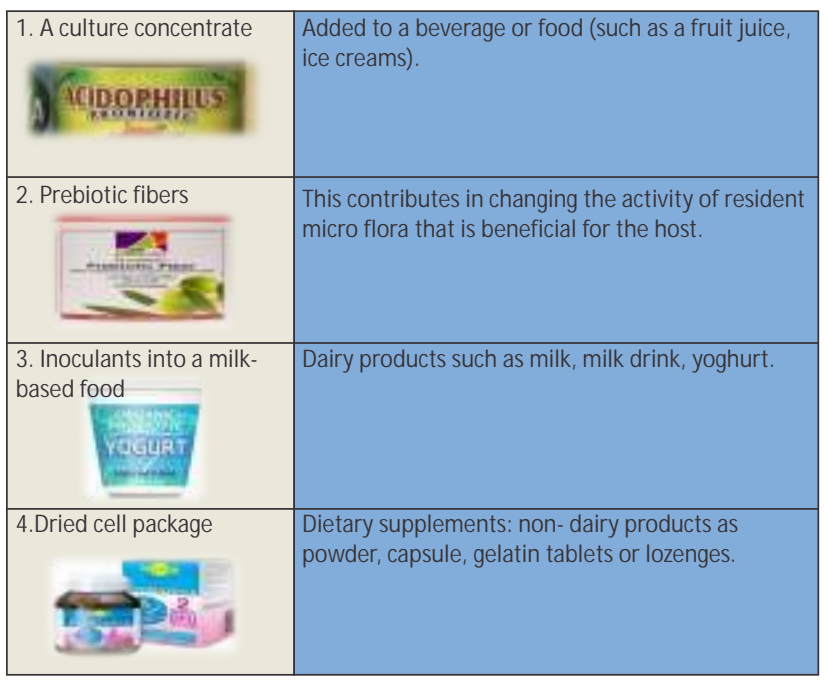

Table 1: Probiotics Products Are Administered In Four Ways

\section{Application of Probiotics to Oral Health}

\section{A. Probiotics and dental caries}

Dental caries is a multifactorial disease of bacterial origin that is characterized by acid demineralization of the tooth enamel $^{(9)}$. To have a beneficial effect in limiting or preventing dental caries, a probiotic must be able to adhere to dental surfaces and integrate into the bacterial communities making up the dental biofilm. The advantage of incorporating probiotics into dairy products lies in their capacity to neutralize the acidic conditions ${ }^{(10)}$.

Comelli and colleagues reported that out of 23 bacterial strains used in the dairy industry, Streptococcus thermophilus and Lactobacillus lactis ssp. lactis were the only ones with the capacity to integrate into a biofilm present on the hydroxyapatite surface and to interfere with thedevelopment of cariogenic species Streptococcus sobrinus ${ }^{(11)}$.

Several clinical studies have demonstrated the regular consumption of milk or cheese containing probiotics led to a decrease in the number of cariogenic streptococci in the saliva and a reduction in dental plaque ${ }^{(12,19)}$. M ore recently it was demonstrated that Weissela cibaria had the capacity to inhibit, both in vitro and in vivo, biofilm formation by Streptococcus mutans and to prevent proliferation of this bacterial strains ${ }^{(13)}$.

\section{B. Probiotics and periodontal disease}

Periodontal disease is classified into 2 types: gingivitis and periodontitis. Gingivitis is characterized by inflammation limited to the unattached gingival(terminal edge or border of the gingiva surrounding the teeth in a collar- like fashion), whereas periodontitis is a progressive, destructive disease that affect all supporting tissues of the teeth, including the alveolar bone ${ }^{(14)}$. There are few experimental studies exploring probiotics use in periodontal diseases, partly reflecting a poorer understanding of the precise etiology of the disease and of the conditions that promote health.

Riccia and colleagues recently studied the antiinflammatory effects of Lactobacillus brevis in a group of patients with chronic periodontitis. The treatment which involved sucking lozenges containing L. brevis over a period of 4 days, led to improvement in the targeted clinical parameters (plaque index, gingival index, bleeding on probing) for all patients. In that study a significant reduction in salivary levels of prostaglandins and matrix metalloproteinases (MMPs) was also observed. The authors suggested that the beneficial effects of $L$. brevis could be attributed to its capacity to prevent the production of nitric oxide and, consequently, the release of prostaglandins and activation of M M Ps induced by nitric oxide ${ }^{(15)}$.

Various studies have reported the capacity of Lactobacilli to inhibit the growth of periodontopathogens, including Porphyromonus gingivalis, Prevotella intermedia and 
Aggregatibacter actinomycetemcomitans ${ }^{(16)}$

\section{Probiotics and Halitosis}

Halitosis has many causes (including consumption of particular foods, metabolic disorders, respiratory tract infections), but in most cases it is associated with the imbalance in the commensal micro flora in the oral cavity. More specifically, halitosis results from the action of anaerobic bacteria that degrade salivary and food proteins to generate amino acids, which are in turn transformed into volatile sulphur compounds, including hydrogen sulphide and methanethiol. There have also been clinical and laboratory studies of probiotics in their potential of preventing halitosis ${ }^{(17)}$.

Kang and colleague reported the capacity of various strains of W.cibaria to inhibit the production of volatile sulphur compounds by Fusobacterium nucleatum. They concluded that this beneficial effect resulted from the production of hydrogen peroxide by W.cibaria, which inhibited the proliferation of F.nucleatum. These authors also found that gargling with a solution containing W.cibaria was associated with the net reduction in the production of hydrogen sulphide and methanethiol and consequently a

\section{References}

1. Laetitia Bonifait, Fatiha Chandad, Daniel Grenier. probiotics for oral health: myth or reality. Jcan Dent Assoc. 2009 oct; 75(8) : 585-90.

2. Parvez S, Malik KA, Ah Kang S, Kim HY. Probiotics and their fermented food products are beneficial for health. J Appl Microbiol. 2006; 100(6): 1171-85.

3. Isolauri E. Probiotics in human disease. Am J Clin Nutr. 2001; 73(6): 1142S- $6 \mathrm{~S}$.

4. Food and Health Agricultural Organization of the United Nations and World Health Organization. Guidelines for the evolution of probiotics in food. joint FAO/WHO Working Group Report on Drafting Guidelines for the evolution of probiotics in Food. 2002. available: ftp://ftp.fao.org/es/esn/food/wgreport2.pdf (accessed 2014 December 23).

5. Fernandez AF, Domingo TA, David P, Diago M P. Probiotic treatment in the oral cavity: An update. Med oral Patol Oral Cir Bucal 2010; 15(5):e677-80

6. Gueimonde M, Salminen S. New methods for selecting and evaluating probiotics. Did liver Dis. 2006; 38 (Suppl 2); S242-7.

7. Erickson KL, Hubbard NE. Probiotic immunomodulation in health and disease.J Nutr. 2000; 130 (2SSuppl): 403S- 409S.

8. Stamatova I, M eurman JH. Probiotics: Health benefits in the mouth. AmJ Dent 2009; 22: 329-338.

9. Selwitz RH, Ismail Al, Pitts NB. Dental Caries. Lancet. 2007; 369(9555): 51-9.

10. Jensen $M E$, Wefel JS. Effects of processed cheese on human plaque $\mathrm{pH}$ and demineralization and remineralization. Am J Dent. 1990; 3(5): 217-23. reduction in a bad breath ${ }^{(18)}$.

\section{Conclusion}

Probiotics represent a new era of research in oral medicine, the examination of the close relationships between food and oral health. They are emerging as a fascinating field. The use of probiotics in oral health applications is gaining a momentum.

Preliminary data obtained by various research laboratories have been encouraging, but numerous randomized control studies will be required to clearly establish the potential of probiotics in preventing and treating oral infections. Such studies will allow identification of the probiotics that are best suited for oral use, as well as the most appropriate vehicles: food products (cheese, milk, yoghurt) or supplements (chewing gum, lozenges). Better scientific understanding and extended research of these tiny forms of life and their effects on humans in the treatment of oral diseases might further broaden the field of potential applications. This short communication conveys a very basic knowledge of Probiotics and its application in oral health, which is an integral part of recent advances in the field of Dentistry.

11. Comeli EM, Guggenheim B, Stingele F, Neeser JR. Selection of daory bacterial strains as probiotics for oral health. Eur J oral Sci. 2002; 110(3): 218-24.

12. Näse L, Hatakka K, Savilahti E, Saxelin M, Ponkä A, Poussa T, effect of long term comsumption of probiotic bacterium, Lactobacillus rhamosus GG, in milk on dental caries and caries risk in children. Caries Res. 2001; 35(6):412-20.

13. Kang MS, Chung J, Kim SM, Yang KH, Oh JS. Effects of Weissella cibaria isolateson the formation on Streptococcus mutans biofilm. Caries Res. 2006; 40(5): 418-25.

14. Houle M A, Grenier D, M aladise parodontales: connaissance actuelles. Current concepts in periodontal disease. 2003; 33(7): 331-40.

15. Riccia DN, Bizzini F, Perilli M G, Polimeni A, Trincheiri V, Amicosante G, et al. Anti- inflammatory effects of Lactobacillus brevis (CD2) on periodontal disease. Oral Dis. 2007; 13(4): 376-85.

16. Lactic acid bacteria from healthy oral cavity of Thai volunteers: Inhibition of oral Pathogens. J Appl M icrobiol. 2001; 90(2): 172-9.

17. Scully C, Greenman J. Halitosis (breath odor). Periodontal 2000. 2008; 48: 66-75

18. Kang M S, Kim BG, ChungJ, Lee HC, Oh JS. Inhibitory effects of Weissella cibaria isolates on the production of volatile sulphur compounds. J Clin Periodontol. 2006; 33(3):226-32.

19. Nikawa H, M akihira S, Fukushima H, Nishimura H, Ozaki K, Darmawan S. Lactobacillus reuteri in bovine milk fermented decreases the oral carriage of mutans streptococci. Int j Food M icrobiol 2004; 95(2): 21923. 